\title{
Histological subtype is the most important determinant of survival in metastatic papillary thyroid cancer
}

\author{
Alexandra Chrisoulidou ${ }^{1 \dagger}$, Maria Boudina ${ }^{1 \dagger}$, Athanasios Tzemailas², Eleni Doumala', Pashalia K lliadou', \\ Frideriki Patakiouta ${ }^{3}$ and Kalliopi Pazaitou-Panayiotou ${ }^{1 *}$
}

\begin{abstract}
Background: Papillary thyroid cancer (PTC) comprises the commonest type of thyroid cancer and carries the highest rate of survival. However, when metastatic disease occurs, survival is significantly affected.

Methods: We aimed to identify prognostic histopathological and clinical factors that modify survival in metastatic PTC. All cases of metastatic PTC treated at our department in the last 20 years were reviewed and analyzed.

Results: Histological subtype was the most important determinant of survival, as classic PTC demonstrated clearly improved survival compared to follicular subtype of PTC and other less frequently seen histological subtypes. The instant risk of death for the other histological subtypes was 4.56 times higher than the risk for the classic papillary type. Overall, a 10-year survival of $76.6 \%$ in our patients was seen.

Conclusions: Patients with aggressive variants of PTC are more at risk for the development of metastatic disease. In these patients, established treatment modalities (surgery, radioiodine therapy) should be offered promptly, as well as close follow-up.
\end{abstract}

Keywords: papillary thyroid carcinoma, distant metastases

\section{Background}

Differentiated thyroid cancer, comprising papillary and follicular thyroid cancer, generally carries a good prognosis. Papillary thyroid cancer (PTC) is the most frequent type of thyroid malignancy and its metastases are usually lymphatic [1]. The risk of distant metastases, usually to the lung, mediastinal lymph nodes and bone, is greater in follicular than in papillary carcinoma [2]. Distant metastases from PTC may occur with a frequency ranging from $1.73-8.4 \%$ in most studies [3,4]. The most common site of distant metastases from PTC is the lung followed by mediastinal lymph nodes [5]. Less often, distant metastases may appear in bones [6], central nervous system $[7,8]$, liver [9], pericardium and pleura [10], kidney [11], pancreas [12], skin and muscle

\footnotetext{
* Correspondence: kpazaitou@in.gr

† Contributed equally

${ }^{1}$ Department of Endocrinology \& Endocrine Oncology, Theagenio Cancer Hospital, Thessaloniki 54007, Greece

Full list of author information is available at the end of the article
}

[13], gastrointestinal tract [14]. As effective treatment may not exist for many of these patients, it is of paramount importance to identify, if possible, those who are at greater risk for developing metastatic disease.

A limited number of retrospective studies have analyzed the prognostic factors, which affect clinical outcome in metastatic PTC. Prognostic factors as sex and age, tumor size, histologic type, tumor infiltration, vascular or lymphatic invasion, have been shown to affect survival in these patients [15]. However, most studies looked into prognostic factors in differentiated thyroid cancer, including both papillary and follicular thyroid cancer in the analysis. In recent years, marked differences in prognostic factors, clinicopathologic features and treatment necessitate the distinction of these two entities [4]. Even in patients with metastatic disease, the overall survival in papillary thyroid cancer is higher than in follicular cancer [16].

In this retrospective study we aimed to investigate patients with metastatic PTC only in order to delineate

\section{Ciomed Central}


specific prognostic factors affecting survival in this rare entity. Within this group, we subdivided patients according to histologic subtype, and studied the clinical and histological characteristics and the received treatment modalities during a mean follow-up of 9 years. Using multivariate analysis, we estimated the factors that significantly affect survival in metastatic PTC.

\section{Patients and methods}

We retrospectively reviewed the records of 1550 patients who had PTC. From this cohort, we identified 52 patients (29 females and 23 males) who presented with or developed (during follow up) distant metastatic disease. For all patients we collected data regarding histological features, age at diagnosis, site of distant metastases, treatment modalities and outcome of the disease. All patients were followed up at the Department of
Endocrinology \& Endocrine Oncology of Theagenio Cancer Hospital from 1988-2009. Patients' characteristics are shown in Table 1. Tumor, lymph nodes and metastases (TNM) staging at the time of diagnosis is shown in table 2.

The diagnosis of distant metastases was based on whole body scan findings and elevated thyroglobulin levels and was verified by computed tomography or MRI. Whenever feasible, biopsy of the metastatic lesions confirmed the diagnosis. Upper mediastinal metastases were not considered as distant. Metastases were classified according to the site of involvement. Histological classification was in accordance with WHO classification 2004 [17].

In all patients work-up included 1) measurements of thyroglobulin, TSH and free thyroxine on suppressive therapy and 2) neck ultrasound annually. Diagnostic

Table 1 Characteristics of the $\mathbf{5 2}$ patients with metastatic PTC

\begin{tabular}{|c|c|c|}
\hline & Number of patients & Number of deaths (\%) \\
\hline \multicolumn{3}{|l|}{ Age (years) } \\
\hline$>19$ & $7(4 \mathrm{~F} / 3 \mathrm{M})$ & $1(1 \mathrm{M})(14.3 \%)$ \\
\hline $19-45$ & $10(6 \mathrm{~F} / 4 \mathrm{M})$ & $4(3 \mathrm{~F} / 1 \mathrm{M})(40.0 \%)$ \\
\hline$<45$ & 35 (19F/16M) & $16(6 \mathrm{~F} / 10 \mathrm{M})(45.7 \%)$ \\
\hline \multicolumn{3}{|l|}{ Sex } \\
\hline Males & 23 & 12 \\
\hline Females & 29 & 9 \\
\hline \multicolumn{3}{|l|}{ Histology } \\
\hline Classic papillary & 24 & \\
\hline Follicular variant & 20 & \\
\hline Papillary with low differentiation of the cells & 6 & \\
\hline Insular & 1 & \\
\hline Columnar & 1 & \\
\hline Size of tumor (mm) & $33(7-80)$ & \\
\hline Multifocal tumors & $27(15 \mathrm{~F} / 12 \mathrm{M})$ & \\
\hline Bilateral tumors & $25(13 \mathrm{~F} / 12 \mathrm{M})$ & \\
\hline Invasion of tumor capsule & 4 & \\
\hline Absence of tumor capsule & 34 & \\
\hline Thyroid capsule invasion & 43 & \\
\hline Extrathyroidal invasion & 38 & \\
\hline Vascular infiltration & 17 & \\
\hline \multicolumn{3}{|l|}{ Presence of metastases } \\
\hline At diagnosis & 17 & \\
\hline During follow-up & 35 & \\
\hline Years of follow-up (years) & $8(1-29)$ & \\
\hline \multicolumn{3}{|l|}{ Thyroidectomy } \\
\hline$\Pi$ & 46 & \\
\hline NTT & 6 & \\
\hline Total RAI dose (mCi) & $360(100-1500)$ & \\
\hline Thyroglobulin at $1^{\text {st }}$ RAI & $121(1.9-4000)$ & \\
\hline
\end{tabular}

Data as median (range); F: female, M: male, $\mathrm{T}$ : total thyroidectomy, NTT: near total thyroidectomy. 
Table 2 TNM staging of patients at initial diagnosis

\begin{tabular}{|c|c|c|c|c|c|c|c|}
\hline & \multicolumn{3}{|c|}{ NO $(n=20)$} & \multicolumn{3}{|c|}{ N1 ( $n=32)$} & \multirow{2}{*}{$\begin{array}{l}\text { Total }(n=52) \\
n\end{array}$} \\
\hline & $n$ & & $n$ & $n$ & & $n$ & \\
\hline \multirow[t]{2}{*}{$T 1$} & & MO & 2 & & MO & 1 & \\
\hline & 3 & M1 & 1 & 3 & $\mathrm{M} 1$ & 2 & 6 \\
\hline \multirow[t]{2}{*}{$\mathrm{T} 2$} & & MO & 1 & & MO & 2 & \\
\hline & 1 & M1 & 0 & 3 & M1 & 1 & 4 \\
\hline \multirow[t]{2}{*}{ T3 } & & MO & 10 & & MO & 9 & \\
\hline & 12 & M1 & 2 & 16 & $\mathrm{M} 1$ & 7 & 28 \\
\hline \multirow[t]{2}{*}{$\mathrm{T4}$} & & Mo & 2 & & MO & 3 & \\
\hline & 4 & M1 & 2 & 10 & M1 & 7 & 14 \\
\hline
\end{tabular}

$\mathrm{T}$ : tumor, $\mathrm{N}$ : lymph nodes, M: metastases, $\mathrm{n}$ represents the number of patients in each category

According to AJCC Cancer Staging Manual, Sixth Edition (2002) published by Springer-Verlag, Inc., New York.

whole body scans and thyroglobulin after thyroxine withdrawal were performed at 9-12 months after treatment with ${ }^{131} \mathrm{I}$ and when necessary thereafter. The Institutional Review Board approved the study.

\section{Statistical analysis}

The Cox proportional hazards model was used for the assessment of possible predictors of survival. Variables with $\mathrm{p}<0.20$ in the univariate analysis were included in the multivariate analysis. Forward stepwise methodology was used for the multivariate analysis. Variables with $\mathrm{p}<0.05$ were considered statistically significant in this step. Kaplan-Meier plots were constructed in order to depict survival. PASW 18.0 (IBM-SPSS Inc., Chicago, IL) was used for data analysis. Factors considered for prediction of survival were summarised in Table 3.

\section{Results}

Fifty-two patients (29 females and 23 males) were found to have distant metastases. Most patients were above 45 years of age ( 35 out of 52 patients). Twenty-two patients (42.3\%) had distant metastases at the time of diagnosis (11 women and 11 men) and 30 patients (57.7\%) developed metastatic disease during follow-up. Tumor size was $\geq 2 \mathrm{~cm}$ in 39 patients. Regional lymph node metastases were present in 30 patients. All patients had total or near total thyroidectomy. Clinical characteristics of the patients and specific characteristics of the tumors are shown in Table 1.

Twenty-four patients had classic papillary thyroid cancer, 20 patients follicular variant of papillary cancer, 1 had papillary carcinoma with insular components and 1 patient had columnar cell variant of papillary carcinoma. The remaining 6 cases exhibited papillary cancer with low differentiation of the cells (with focal follicular elements in 2 patients).
Table 3 Factors considered for prediction of survival

\begin{tabular}{ll}
\hline Factor & Significance \\
\hline Sex & 0.523 \\
\hline Age & 0.132 \\
\hline Histology & 0.004 \\
\hline Bultaterality & 0.887 \\
\hline Type of surgery & 0.292 \\
\hline Size of tumor & 0.603 \\
\hline Lymph node metastases at operation & 0.392 \\
\hline Thyroid parenchyma invasion & 0.263 \\
\hline Thyroid capsule invasion & 0.502 \\
\hline Extrathyroidal invasion & 0.095 \\
\hline Vessel invasion & 0.863 \\
\hline Metastatic disease from diagnosis & 0.058 \\
\hline First site of metastasis & 0.180 \\
\hline Uptake at ablation & 0.874 \\
\hline TSH on T4 withdrawal & 0.568 \\
\hline Thyroglobulin on T4 withdrawal & 0.782 \\
\hline Total 131 I mCi & 0.799 \\
\hline Years to metastasis & 0.426 \\
\hline
\end{tabular}

The commonest sites of metastatic disease were lung (32 patients), followed by bone (13 patients), lower mediastinum (6 patients) extracervical soft tissue (4 patients), central nervous system (4 patients), pleura (4 patients), liver (1 patient), and oeshophagus (1 patient). Multiple site metastases were found in 14 patients.

Table 3 indicates the factors affecting survival in our series: histology comprised the most significant factor in the analysis, the classic papillary type carrying significantly improved survival than follicular and other subtypes of papillary thyroid cancer. The instant risk of death for the other histological subtypes was 4.56 times higher than the risk for the classic papillary type. The other parameters tested did not affect survival significantly.

Mortality ranged according to age (table 1), with the worst outcome in patients above 45 years of age. Overall 5 -year survival in metastatic papillary thyroid cancer was $88.2 \%, 10$-year $76.6 \%$ and 15 -year survival $35.8 \%$ (for 10 patients). Cumulative survival is shown in Figure 1.

\section{Discussion}

Only a few studies so far examined specific factors affecting survival in patients with PTC, as in most studies patients with papillary and follicular thyroid cancer were included. The striking finding in this study was that histological variant plays the most significant role in patient's survival in metastatic PTC. The classic papillary type of PTC demonstrated improved prognosis compared to other papillary cancer variants. 


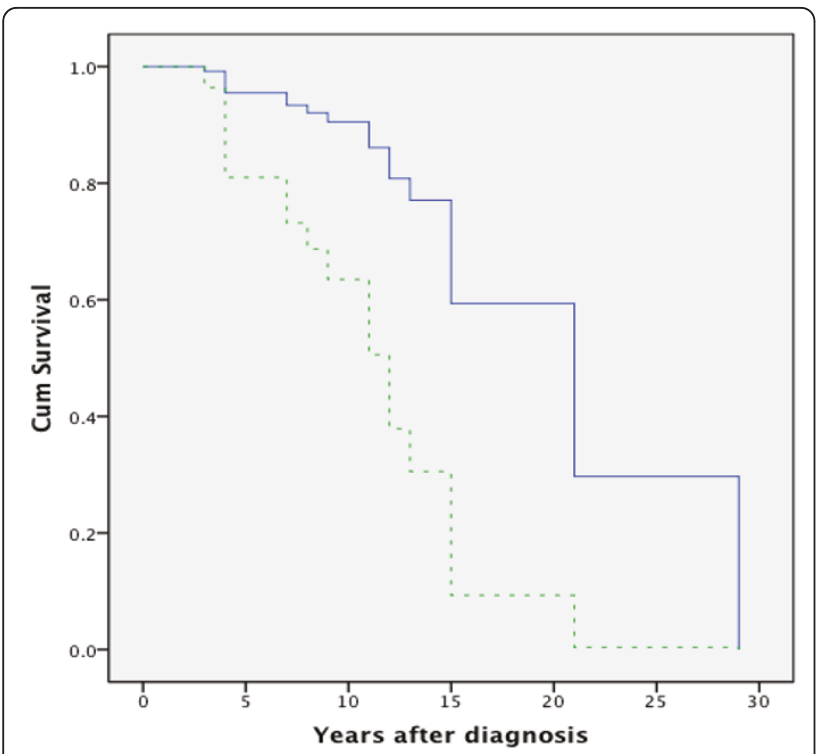

Figure 1 Survival over time in patients with classic PTC (continuous line) and PTC variants (dotted line).

Although papillary thyroid carcinoma carries the most favorable prognosis amongst all types of thyroid cancer, distant metastatic disease may occur with subsequent compromise in patient's survival. Even in the presence of metastatic disease, papillary thyroid cancer in our series has an overall 10 -year survival of $76.6 \%$. In general, disease-related mortality varies greatly in PTC: papillary microcarcinomas exhibit no mortality at all [18], even in the presence of distant metastases [19]. In other series with larger PTCs, 10-year survival ranged from 14-80\% [20-22], with limited survival in older patients. Old age is a predictor of worse prognosis, although an exact cut off point was not uniformly identified [23]. In this study, we did not observe statistical differences in survival according to age, although we also observed an increase in mortality in patients above 45 years of age.

Previous studies indicated many factors, as capsular infiltration, extrathyroidal extension and lymph node metastases at diagnosis as unfavorable prognostic factors for persistent disease or recurrences [24]. Cervical lymph node metastases have been related to poor prognosis occurring synchronously or metachronously to diagnosis [25], although this was not seen in the present study. Extranodal invasion and perithyroidal invasion to muscles and soft tissues showed a higher incidence of distant metastases and death [26]. The presence of vessel invasion was associated, as in other reports, with poor prognosis, although in our series this association had a marginal significance (Table 2).

Although differentiated thyroid cancer is frequently seen in women, in patients with metastatic PTC the female: male ratio was $1.26: 1$, in accordance with the general notion that male gender adversely affects outcome in differentiated thyroid cancer. In the studied group $52 \%$ of males and $31 \%$ of females died during follow-up, however this was not significant probably due to small numbers. Histology increased nearly 5 -fold the risk of death in patients with PTC variants other than the classic papillary type.

In keeping with other reports, we observed lung as the primary metastatic site, followed by bone, multiple site involvement and other, less frequently seen, affected organs. The development of rare metastases, as CNS, liver and extracervical soft tissue metastases, indicates the importance of close clinical follow-up in these patients.

In conclusion, the histological subtype in metastatic PTC determines survival in a significant way. As a result, patients with follicular and other uncommon subtypes of PTC that present with or develop distant metastatic disease should be vigorously treated with surgery, where appropriate, radioiodine therapy and should also be considered for inclusion to studies concerning new therapies, like tyrosine kinase inhibitors.

\section{Author details}

${ }^{1}$ Department of Endocrinology \& Endocrine Oncology, Theagenio Cancer Hospital, Thessaloniki 54007, Greece. ${ }^{2}$ Department of Nuclear Medicine, Theagenio Cancer Hospital, Thessaloniki 54007, Greece. ${ }^{3}$ Department of Pathology, Theagenio Cancer Hospital, Thessaloniki, Greece.

\section{Authors' contributions}

KPP conceived and coordinated the study. MB, PKI, ED gathered the data. $M B$ and AT prepared the database and inserted the relevant data. FP examined the histological material. AC did the statistical analysis and drafted the tables. KPP and AC wrote the manuscript. All authors read and approved the final manuscript.

\section{Competing interests}

The authors declare that they have no competing interests.

Received: 16 March 2011 Accepted: 19 July 2011

Published: 19 July 2011

\section{References}

1. Salter KD, Andersen PE, Cohen Jl, Schuff KG, Lester L, Shindo ML, Sauer D, Gross ND: Central node metastases in papillary thyroid carcinoma based on tumor histologic type and focality. Arch Otolaryngol Head Neck Surg 2010, 136:692-696.

2. Maxon HR, Smith HS: Radioiodine-131 in the diagnosis and treatment of metastatic well-differentiated thyroid cancer. Endocrinol Metab Clin North Am 1990, 19:685-671.

3. Sugitani I, Fujomoto Y, Yamamoto N: Papillary thyroid cancer with distant metastases:survival predictors and the importance of local control. Surgery 2008, 143:35-42.

4. Lang BH-H, Lo CY, Chan WF, Lam AK, Wan KY: Classical and follicular variant of papillary thyroid carcinoma: a comparative study on clinicopathologic features and long-term outcome. World J Surg 2006, 30:752-758.

5. Lin JD, Chao TC, Chou SC, Hsueh C: Papillary thyroid carcinomas with lung metastases. Thyroid 2004, 14:1091-1096.

6. Do MY, Rhee Y, Kim DJ, Kim CS, Nam KH, Ahn CW, Cha BA, Kim KR, Lee HC, Park CS, Lim SK: Clinical features of bone metastases resulting from thyroid cancer: a review of 28 patients over a 20 -year period. Endocr J 2005, 52:701-707. 
7. Parker LN, Wu SY, Kim DD, Kollin J, Prasasvinichai S: Recurrence of papillary thyroid carcinoma presenting as focal neurologic deficit. Arch Intern Med 1986, 146:1985-1987.

8. Holmquest DL, Lake P: Sudden hemorrhage in metastatic thyroid carcinoma of the brain during treatment with iodine-131. J Nucl Med 1976, 17:307-309.

9. Agriantonis DJ, Hall L, Wilson MA: Utility of SPECT/CT as an adjunct planar whole body I-131 imaging: liver metastases from papillary thyroid cancer. Clin Nucl Med 2009, 34:247-248.

10. Mizukami Y, Michigishi T, Nonomura A, Hashimoto T, Terahata S, Nogushi M, Hisada K, Matsubara F: Distant metastases differentiated thyroid carcinomas: a clinical and pathologic study. Hum Pathol 1990, 21:283-290.

11. Sardi A, Agnone DM, Pellegrini A: Renal metastasis from papillary thyroid cancer. J Louisiana State Med Soc 1992, 144:416-420.

12. Borschitz T, Eichhorn W, Fottner C, Hansen T, Schad A, SchadmandFischer S, Weber MM, Schreckenberger M, Lang H, Musholt TJ: Diagnosis and treatment of pancreatic metastases of a papillary thyroid carcinoma. Thyroid 2010, 20:93-98.

13. Bruglia M, Palmonella G, Silvetti F, Rutigliano P, Criante P, Marmorale C, Boscaro M, Taccaliti A: Skin and thigh muscle metastasis from papillary thyroid carcinoma. Singapore Med J 2009, 50:61-64.

14. Klubo-Gwiezdzinska J, Morowitz D, Van Nortrand D, Burman KD, Vasko V, Chia S, Deng T, Kulkarni K, Wartofsky L: Metastases of well-differentiated thyroid cancer to the gastrointestinal tract. Thyroid 2010, 20:381-387.

15. Showalter TN, Siegel BA, Moley JF, Baranski TJ, Grisby PW: Prognostic factors in patients with well-differentiated thyroid cancer presenting with pulmonary metastasis. Cancer Biother Radiopharm 2008, 23:655-659.

16. Benbassat CA, Mechlis-Frish S, Hirsch D: Clinicopathological characteristics and long-term outcome in patients with distant metastases from differentiated thyroid cancer. World J Surg 2006, 30:1088-1095.

17. De Lellis RA, Lloyd RV, Heinz PU, Eng C, editors: World Health Organization Classification of Tumours.Pathology and Genetics-Tumours of Endocrine Organs. IARC Press Lyon; 2004.

18. Roti E, Rossi R, Trasforini G, Bertelli F, Ambrosio MR, Busutti L, Pearce EN, Braverman LE, Degli Uberti EC: Clinical and histological characteristics of papillary thyroid microcarcinoma: results of a retrospective study in 243 patients. J Clin Endocrinol Metab 2006, 91:2171-2178.

19. Pellegriti G, Scollo C, Lumera G, Regalbuto C, Vigneri R, Belfiore A: Clinical behaviour and outcome of papillary thyroid cancers smaller than $1.5 \mathrm{~cm}$ in diameter: study of 299 cases. J Clin Endocrinol Metab 2004, 89:3713-3720

20. Dinneen SF, Valimaki MJ, Bergstralh EJ, Goellner JR, Gorman CA, Hay ID: Distant metastases in papillary thyroid carcinoma: 100 cases observed at one institution during 5 decades. J Clin Endocrinol Metab 1995, 80:2041-2045.

21. Durante C, Haddy N, Baudin E, Leboulleux S, Hartl D, Travagli JP, Caillou B, Ricard M, Lumbroso JD, De Vathaire F, Schlumberger M: Long-term outcome of 444 patients with distant metastases from papillary and follicular thyroid carcinoma:benefits and limits of radioiodine therapy. $J$ Clin Endocrinol Metab 2006, 91:2892-2899.

22. Ito $Y$, Masuoka H, Fukushima M, Inoue H, Kihara M, Tomoda C, Higashiyama T, Takamura Y, Kobayashi K, Miya A, Miyauchi A: Prognosis and prognostic factors of patients with papillary carcinoma showing distant metastasis at surgery. Endocr J 2010, 57:523-531.

23. Kakudo K, Tang W, Ito Y, Nakamura Y, Yasuoka H, Morita S, Miyauchi A: Papillary carcinoma of the thyroid in Japan: subclassification of common type and identification of low risk group. J Clin Pathol 2004, 57:1041-1046.

24. Mercante G, Frasoldati A, Pedroni C, Formisano D, Renna L, Piana S, Gardini G, Valcani R, Barbieri V: Prognostic factors affecting neck lymph node recurrence and distant metastasis in papillary microcarcinoma of the thyroid:results of a study in 445 patients. Thyroid 2009, 19:707-716.

25. Baek SK, Jung KY, Kang SM, Kwon SY, Woo JS, Cho SH, Chung EJ: Clinical risk factors associated with cervical lymph node recurrence in papillary thyroid carcinoma. Thyroid 2010, 20:147-152.

26. Sebastian SO, Gonzalez JM, Paricio PP, Perez JS, Flores DP, Madrona AP, Romero PR, Tebar FJ: Papillary thyroid carcinoma:prognostic index for survival including the histologic variety. Arch Surg 2000, 135:272-277.

doi:10.1186/1756-6614-4-12

Cite this article as: Chrisoulidou et al: Histological subtype is the most important determinant of survival in metastatic papillary thyroid cancer. Thyroid Research 2011 4:12.

\section{Submit your next manuscript to BioMed Central and take full advantage of:}

- Convenient online submission

- Thorough peer review

- No space constraints or color figure charges

- Immediate publication on acceptance

- Inclusion in PubMed, CAS, Scopus and Google Scholar

- Research which is freely available for redistribution

Submit your manuscript at www.biomedcentral.com/submit 